\title{
ARTICLE \\ The Promise of Blockchain Technology for Global Securities and Derivatives Markets: The New Financial Ecosystem and the 'Holy Grail' of Systemic Risk Containment
}

\author{
Emilios Avgouleas ${ }^{1,2,3} \cdot$ Aggelos Kiayias $^{4,5}$
}

Published online: 28 February 2019

(c) The Author(s) 2019

\begin{abstract}
Weaknesses in investor control over their investments and in warehousing systemic risk in modern Financial Market Infrastructure (FMI) are the result of a combination of market failures and of structural flaws deeply ingrained in modern financial markets. Yet the utility of complex FMI comprising long custodial chains and large global Central Counterparties (CCPs) for the operation of modern markets is not seriously disputed. The change in the technology paradigm with the introduction of DLT systems for securities and derivatives FMI can increase investor control, the efficiency of risk management and, to some extent, augment the distribution of systemic risk. It can thus create a more diverse and resilient financial ecosystem. This cross-disciplinary paper identifies a multitude of reasons that favour a paradigm shift in FMI technology. It also sketches a comprehensive blockchain-based framework for the development of permission-based platforms for derivatives clearing and settlement and the handling of liquidity shortages within DLT systems. Arguably, the impact of technological change should lead to a reduction of industry rents for the benefit of end investors and of the end users of finance (entrepreneurs and businesses) enhancing market welfare. Therefore, the use of blockchain technology in FMI can transform the structure and future direction of the financial services industry as a whole.
\end{abstract}

Keywords CCPs $\cdot$ Financial stability $\cdot$ DLT $\cdot$ Blockchain $\cdot$ Systemic risk $\cdot$ Ethereum · Derivatives · Margins · Clearing and settlement · Liquidity · Adverse selection $\cdot$ Intermediated securities

Emilios Avgouleas

emilios.avgouleas@ed.ac.uk

Extended author information available on the last page of the article 


\section{Introduction}

In contemporary financial markets once a trade in securities is concluded the services of a number of intermediaries have to be employed to create finality (inviolable legal and material certainty) about the transfer of the asset or cash involved. A more complex process is employed in the case of derivatives contracts with respect to transaction clearing and settlement, which also involves the transfer of collateral to safeguard the execution/performance of the derivative contract concerned. The execution of a derivative contract depends on whether the contract is an exchangetraded derivative or an over-the-counter (OTC) contract. OTC derivative contracts can be quite bespoke and flexible as to the choice of underlying assets, maturity, size of contract, and terms of delivery. For OTC derivative contracts that do not use Central Counterparty (CCP) infrastructure, execution is left to the two parties to the contract to arrange. Settlement usually takes place over a number of days. However, during the settlement time for the transaction, each party runs the risk that the other party may become insolvent or another occurrence may take place so that the transaction is not completed (counterparty risk). Where the OTC contract is CCP cleared the CCP is interposed between the parties absorbing the credit risk.

Financial Market Infrastructure (FMI) arrangements (so-called market 'plumbing') are vital for the orderly operation of the global financial system and involve the employment of expensive technology and complex technical and legal infrastructure. In the aftermath of the 2008 crisis and following agreement within the G20, the centralisation of OTC derivatives' clearing and settlement became one of the centrepieces of reform legislation ${ }^{1}$ to battle systemic risk. This was linked in the case of OTC markets to, first, the contagion emanating from the possible string of defaults suffered by derivatives counterparties in the event of a crisis when collateral becomes scarce, secondly, the formation of invisible links of interconnectedness in OTC markets between different market actors and segments, and, third, the risk of firesales, generated by stressed traders trying to squeeze cash to meet margin calls to avoid default. $^{2}$

Under the new regulations the central counterparty will be notified of the contract and take the place of the trading counterparties by means of legal novation. As a result, the bilateral contract is replaced by two opposing contracts with the counterparty. The CCP provides protection to non-defaulting members (and, indirectly, their clients) from the inability of a defaulting member to meet its obligations. ${ }^{3}$

CCPs use a number of risk mitigation techniques including high scale netting to compress open positions to, in principle, manageable chunks of risk. In addition, other arrangements are in place to mitigate CCPs' exposure and the possibility of

\footnotetext{
${ }^{1}$ Title VII and Title VIII of the Dodd-Franck Act (Wall Street Reform and Consumer Protection Act (Pub. L. 111-203, H.R. 4173) and the EU Market Infrastructure Regulation (EMIR), Regulation (EU) No. 648/2012 on OTC derivatives, central counterparties and trade repositories [2012] OJ L201/1-59.

2 Avgouleas (2012), ch. 2.

${ }^{3}$ See ASX Clearing Party Limited, Clearing Participant Default-An Overview, p 3, available at https ://www.asx.com.au/documents/clearing/131001_Default_Management_-_Public_Information_Docum ent_v2.pdf. Accessed 10 January 2019).
} 
failure including a dynamic process for the provisioning of open positions through high grade collateral, so-called margins. ${ }^{4}$ Then, members' pre-funded commitments and a chunk of CCP owners' equity can be employed to absorb losses.

The current FMI for both securities and derivatives trading and settlement gives rise to a number of social costs. In the case of securities, a chain of custodians hold in a sequence the dematerialised security which investors control only indirectly. Namely, asset dematerialisation and fungibility has led to the creation of so-called intermediated securities which might have improved system efficiency by increasing liquidity but have also given rise to a number of undesirable consequences. These may be summarised as follows: (a) loss of control over the security by the end of the investor/ultimate owner, (b) possible legal uncertainty, and (c) the risk that collateral re-use can induce credit creation through the repo markets and other channels for secured funding, which, ultimately may become a systemic concern, especially under conditions of generalised illiquidity. ${ }^{5}$ In the case of OTC derivatives markets, risk concentration within central counterparties gives rise to systemic risk concerns, especially in the event of a CCP failure.

Regulation has no clear answer for many of these challenges. In the case of the mandatory centralisation of OTC derivatives clearing and settlement, regulation has given rise to unintended consequences. On the other hand, in recent years the emergence of blockchain-based platforms with more sophisticated features, including permission-based systems for the transfer and trading of cryptoassets, have raised the prospect of using the underlying technology to address some of the social costs associated with contemporary securities and derivatives trading and clearing and settlement. The blockchain technology used by systems like the Ethereum platform or Ripple ${ }^{6}$ meaningfully evolved the technology that underlined the Bitcoin blockchain. Distributed Ledger Technology (DLT) has already been reliably introduced in the trade finance environment with significant expected gains in terms of time and the transaction costs of document processing. ${ }^{7}$ In addition, two major international securities exchanges have also declared their intention to eventually move to a fully blockchain operated trading and clearing environment. ${ }^{8}$

Given the fact that the industry either experiments on a large scale or has moved to implement the new technology, this article postulates that this is the right time to consider the eventual benefits and some of the risks of the introduction of blockchain technology for securities and especially derivatives clearing and settlement. It also identifies the essential decision-making and risk-management techniques that will make such a transition credible. One of the most important and least discussed aspects of the expected change from the introduction of blockchain technology is

\footnotetext{
${ }^{4}$ For an overview see Pirrong (2009).

5 Gorton and Metrick (2009).

${ }^{6}$ For more information see https://ripple.com.

7 See 'Hong Kong regulator, banks launch blockchain-based trade finance platform', Reuters.com, 17 July 2018; Ian Allison, 'Banks Take sides as blockchain trade finance race heats up', 17 July 2018, available at https://www.coindesk.com/banks-take-sides-as-blockchain-trade-finance-race-heats-up/.

8 These are the Australian Securities Exchange (ASX 2018) and the Canadian Securities Exchange (CSE 2018).
} 
that it will significantly transform risk management and risk distribution techniques within the financial system while offering investors more control over their investments and the clearing and settlement process. Thus, this article is undertaking an exploratory discussion of how such a transformation could impact on risk diversification and whether it could act as a restraining force on excessive speculation. In Sect. 5 below we offer a first principles solution on how the DLT technology could work in a derivatives trading, clearing and settlement environment, especially as regards margin calls.

Assuming network effects for DLT platforms, due to higher transparency and lower transactions costs, deep pools of liquidity would be reallocated. DLT systems would be likely to attract relatively more standardised OTC derivatives contracts, which will be easy and cheap to manage during the lifetime of product and clear, or tailor-made yet not excessively risky contracts, which the increased transparency of blockchain systems and the employment of sophisticated algorithms may make easier to price. At the same time, it is not envisaged that CCPs will cease to exist but rather that they will operate in order to clear and absorb risks from the more complex and risky end of the derivatives market, a service for which they will charge higher fees. And while any such development could make CCPs more risky, at the same time the possible existence of several competing systems to clear OTC derivative markets contracts would turn CCPs to much less important warehouses of systemic risk and thus making them easier to resolve. This would alleviate one of the thorniest problems of global finance since big cross-border CCPs are often regarded as being, in practice, Too-Big-To-Fail (TBTF) in the highest order. ${ }^{9}$

Finally, if reduced volumes meant less loss-absorption capacity for CCPs to clear highly complex and risky derivatives, CCPs would simply decline to accept such products for clearing. CCPs' reasoned decision to decline accepting a product for clearing could send a strong message to the market and the boards of institutional investors that trading in such normally highly speculative products ought to be abandoned, unless doing so is absolutely necessary for hedging purposes.

Accordingly, this article argues that the change in the trading, clearing and settlement technology will lead to the creation of uncorrelated clusters of risk through a new generation of DLT-operated liquidity and risk pools that will compete with CCPs for the clearing and settlement business. And while the platform itself will operate on the basis of margin requirements including margin variations/calls and a guaranty fund, a so-called treasury, liquidity management on such a platform may become more efficient than within CCPs. This may be the case either as a result of increased transparency and better pricing but also due to the (discussed in Sect. 7) possibility of equipping the platform with a special functionality that could activate extraordinary liquidity management mechanisms.

\footnotetext{
${ }^{9}$ E.g., a recent IMF paper notes: '[T] he combination of mandatory clearing and concentration of counterparty risk into a central infrastructure increases the risk of failure of the infrastructure itself. This issue arises for the largest CCPs, which clear OTC derivative products in accordance with the new mandates...' Singh and Turing (2018), p 4. For CCP resolution standards see Financial Stability Board (FSB) (2017d).
} 
While it is very hard to predict the level of market and risk transformation that DLT systems will bring in the future, their increased fidelity and reliability means that the present push by global regulators for further centralisation which leads to stronger levels of CCP concentration is misguided. But the benefits that the new technology may bring to ecosystem resilience may not materialise if regulators help CCPs to simply strengthen their position by hijacking the new technology and making it to serve their ends, as they are, of course, capable of doing.

This article is divided into seven sections including the present introduction. Section 2 offers an analytical overview of the key functions of CCPs and the risk mitigation mechanisms they employ leading, in principle, to the containment of clearing and settlement risk. Section 3 will discuss the challenges that CCPs raise for the orderly function and stability of the financial system. Section 4 focuses on risk spillovers from CCPs that can trigger a systemic event. These may emanate from the possible inadequacy of key loss absorption mechanisms and/or interconnectedness. Section 5 explains how a DLT system for derivatives trading, clearing and settlement could be configured/built and the mechanisms advanced blockchain systems can employ which could alleviate risk concentration in financial markets. Section 6 explains how the employment of DLT systems empowers investors and reduces the risks to the financial system from uncontrollable collateral re-use. Section 7 brings the different strands of the present enquiry into a comprehensive conclusion.

\section{Central Counterparties: Risk Mitigation Techniques}

\subsection{Benefits of Centralised Clearing and CCP Operations}

Clearinghouses (CCHs) are a risk management mechanism which enables a market-wide pooling of post-trading liquidity. Becoming the transactional node for all cleared trades and accessing the information about all cleared transactions, the clearinghouse can assess, price, and monitor risks in the market. The collateralisation of derivatives transactions reduces the amount of credit (leverage) implicit in derivatives trades and mutualization (member risk sharing) and equitization (shareholder absorption of losses) shift default losses to the members and (to a lesser extent) the owners of the CCP. In addition, CCPs implement a variety of measures, including auctions to reduce and reallocate the losses resulting from the default of a member. In this way CCPs can reduce disruptions associated with the replacement of defaulted positions. ${ }^{10}$

Most CCPs were originally created by the members of futures exchanges to serve the members' interests by allocating and managing default risk more efficiently. But in contrast to their present conception, CCPs were not designed as macro-prudential institutions with responsibility to improve the safety and soundness of the broader

\footnotetext{
10 Among the many sources cited in this article there are three key papers on which the section draws on more than others and they are Pirrong (2011); Elliott (2013); Carter and Garner (2015).
} 
financial system. ${ }^{11}$ The systemic importance of CCPs has dramatically expanded as a result of Dodd-Frank, EMIR, and other regulatory initiatives around the world that mandate the clearing of derivatives contracts. CCPs contribute to the stability of the financial system in many critical ways. ${ }^{12}$

\subsection{Margin Collections}

One of the most important risk management functions that CCPs have is the (accurate) valuation of the derivatives positions to be cleared. Since trading parties' exposures become CCP exposures after the aforementioned novation process, CCPs demand collateral (or 'margin') from the trading counterparties. Collateral collected as margin serves an important risk mitigation function and it is employed as the first line of defence against counterparty risk $^{13}$ regardless of whether the contract is cleared bilaterally or centrally via a CCP.

The collection of margin by the clearing member from its clearing customers for each trade takes place at the initiation of the trade (initial margin) and on a regular basis (variation margin) for the lifetime of the contract. Variation margin is collected at least daily, but frequently intra-day, based on changes in prices since the last mark-to-market calculation, when CCPs calculate the gains and losses on each portfolio. Those whose contracts have declined in value as a result of these price changes are obligated to transfer collateral to the CCP of an amount equal to this change in market value. This is a variation margin payment.

CCPs set initial margin amounts and the frequency of mark-to-market to contain loss from a cleared position which also reflect CCP estimates of the riskiness of the underlying transaction. On the other hand, while initial margins refer to contract riskiness, they do not cover the creditworthiness of the party to a trade.

In principle, initial margins and variation margins should be sufficient to cover the defaulter's obligations. But the 'defaulter pays' model may never be fully applicable. Because margins are costly, ${ }^{14}$ it is inefficient to collateralize contracts against all possible price movements. Derivatives traders normally trade on credit and the security (collateral) they provide is merely a fraction of the value of any given contract. Accordingly, through their choice of margin levels, CCPs tailor not just their exposures to losses resulting from default but also traders' leverage. ${ }^{15}$ As derivatives traders often have to borrow some of the additional funds or the securities that are required to post as collateral, liquidity might dry up or funding costs and yields might increase, thereby making the choice between borrowing at substantial higher costs and default a stark one. We discuss funding risk in Sect. 4 below.

\footnotetext{
${ }^{11}$ For the systemic concerns raised in connection with the possible failure futures CCPs in the US during the 1987 crash see Bernanke (1990), p 133.

12 See for discussion Kroszner (2011).

13 Pirrong (2011), p 25.

14 Hartzmark (1986), S147.

15 Pirrong (2011), p 3.
} 


\subsection{Netting, Contract Replacement and Auctions}

Netting of offsetting positions as well as netting of exposures across contracts can be a rather effective risk mitigation exercise as it reduces the exposure of contracts at risk of default and of the amounts at risk upon default. Given the centralisation of opposite positions and exposures through the centralisation of clearing, CCPs are in a much better position to make netting an effective risk-reduction mechanism than would happen in a bilateral clearing scenario. In addition, netting of positions across multiple parties reduces the total positions that need to be replaced in the event of default, which tends to mitigate price impact.

The benefits of netting, however, also depend on the scale and scope of CCPs in a way that encourages uniformity/standardisation and concentration, since for every derivatives contract, position opportunities are maximized when a single CCP clears the specific product. ${ }^{16}$

Also CCPs facilitate the orderly transfer of customer positions from financially troubled intermediaries or their orderly replacement through a number of mechanisms including via auctioning off the defaulter's contractual obligations. Since CCP rules allow customer positions to be portable, these can be transferred from the client accounts of a troubled CCP member (held with the CCP) to financially sound member firms. This reduces the likelihood that a defaulter's clients will lose as a result of the default or that their margin money or assets will be encumbered as part of the bankrupt member's estate.

Moreover, centralised CCP auctions for defaulted contracts do not just absorb risk on defaulted contracts, they can also contain price disruptions. ${ }^{17}$ Naturally, well-managed centralized auctions among CCP members can be more liquid than $\mathrm{ad}$ hoc ones, and result in lesser price disruptions. This is particularly important during periods of pronounced uncertainty in the market as liquidity pooled within the CCP can avert the risk of firesales.

\subsection{Risk Equitisation and Mutualisation}

CCPs use members' pre-committed resources and owners' equity as a countercyclical risk absorption buffer allowing them to perform a macroprudential function in containing systemic risk alongside the risk management techniques discussed above. The built-in ex ante loss absorption capacity can, in principle, contain the risk of contagion especially if the resources pooled in the guaranty fund and the CCP's equity are substantially higher than those of a single firm and control the risk of intra-firm contagion for CCP members. This is especially the case where market risks in one segment of a firm's balance sheet can become solvency risks if a worried market declines to refinance the firm's debt, or act as a counterparty for transactions taking place in another segment of the firm's balance sheet. At the same

\footnotetext{
${ }^{16}$ Pirrong (2006); Duffie and Zhu (2011).

${ }^{17}$ Pirrong (2011), p 10.
} 
time, the CCP strengthens the contractual links among clearing members and clearing members and the CCP giving rise to a different source of contagion risk due to interconnectedness.

CCPs typically require their member firms to make contributions to a default fund (or its equivalent). In this way, default losses are shared-mutualized-among the CCP members. Losses in excess of those covered by the defaulter's margin and default fund contribution are drawn from the general default fund. If losses exhaust the fund, CCPs typically obligate the members to make additional contributions. These additional contributions (capital calls) may be capped at an amount equal to the original contribution to the CCP default fund ${ }^{18}$ and they are part of the so-called 'loss waterfall'. ${ }^{19}$ Because of these specific features, the clearinghouse can perform a macroprudential function in mitigating systemic risk: the countercyclical nature of the fund reduces the likelihood of contagion. In some cases, the $\mathrm{CCH}$ owner may intervene after $\mathrm{CCP}$ ' resources including margins and contributions to the guaranty fund have been depleted.

CCHs are today for-profit corporations, or subsidiaries of for-profit corporations. This poses a number of governance problems since shareholders may be tempted to accept for clearance higher risk products which may increase revenue and thus shareholder profit. Namely, since it is the member's pre-funded commitments that will take the first hit in the event of failure, shareholders and their directors may feel tempted to undertake unnecessary risks. This perverse agency problem is to some extent mitigated by the fact shareholders' equity can be used to absorb default losses, so-called skin-in-the-game. ${ }^{20}$

\section{CCP Governance, Moral Hazard and Risk Concentration}

\subsection{Adverse Selection, Moral Hazard, and CCP Governance}

\subsubsection{Adverse Selection}

CCP reallocation of risk can improve welfare by shifting risk from those who bear it at a high cost to those who can bear it at a lower cost. Critically, since all protection mechanisms have costs arising from information and incentive problems-a good example here is the moral hazard and adverse selection associated with deposit insurance or credit default swaps (CDs) — clearing of derivatives trades via CCPs is not an exception. As firms that trade derivatives know more about the risks of particular products than the CCP, these firms tend to over-trade the products for which the CCP underestimates risk, and under-trade the products for which the CCP overestimates risk. Many firms trading derivatives (e.g., large banks, hedge funds)

\footnotetext{
18 Pirrong (2011), p 9.

19 Singh and Turing (2018), pp 5-6.

20 Saguato (2017).
} 
specialize precisely in understanding these risks, ${ }^{21}$ and hence are likely to have better information than CCPs and this is especially true for more complex and novel derivative instruments.

CCP members can, in fact, engage in this behaviour with relative impunity. One of the benefits of clearing, the fact that it makes cleared instruments fungible by making all potential counterparties interchangeable, also tends to reduce the costs that riskier firms incur to trade relative to the costs incurred by lower risk firms. ${ }^{22}$ And while CCPs monitor the creditworthiness of their members, this monitoring is largely based on standards and information (e.g., accounting statements) that do not reflect, in a timely manner, the changes in the creditworthiness of their members. Thus, close monitoring by the CCP only imperfectly controls moral hazard associated with the trades of riskier firms. ${ }^{23}$

\subsubsection{CCP Governance}

CCHs were first formed as transaction cost-saving clubs where risks were pooled and shared among $\mathrm{CCH}$ members who were also the owners of the organisation. However, with the advent of the demutualisation of financial exchanges in the 2000s, $\mathrm{CCHs}$ became parts of larger financial market infrastructure groups in a process of the vertical integration of trading, post-trading, and reporting services. ${ }^{24}$ The four most important derivatives clearing houses are all subsidiaries or internal divisions of publicly listed parent companies which are run to maximize shareholder value providing reduced or no management rights to their members. Given the corporate structure of modern CCHs, agency problems as regards the calibration of CCPs' risk appetite are quite endemic and are a cause of wider concern, since the more products they clear the higher the profit accruing to $\mathrm{CCH}$ shareholders.

One solution that could deal with CCP governance issues is ring-fencing, a technique used to shield one entity from risks originating in other parts of a business group or markets. The best example is the UK's initiative to ring-fence its commercial banks from the investment banking risks undertaken by other entities/divisions of the banking group. ${ }^{25}$ But ring-fencing may also present its own problems, since it would allow those $\mathrm{CCHs}$ that today contribute their own resources to absorb CCP residual losses, when all other sources of funding through the loss waterfall have been exhausted, to withdraw such support. It will also make CCP membership more expensive, since the prospect of operating efficiencies across the $\mathrm{CCH}$ divisions and the cross-use of IT infrastructure, a form of cross-subsidisation of group functions, would disappear.

${ }^{21}$ Telser (1981), p 1.

${ }^{22}$ See Pirrong (2010); Pirrong (2011).

${ }^{23}$ Pirrong (2011), p 14.

${ }^{24}$ Ferrarini and Saguato (2015), p 285.

${ }^{25}$ Financial Services (Banking Reform) Act 2013 c. 33. 


\subsection{Prudential Controls: Regulatory Checks on CCPs' Decision-Making and Stress-Testing}

The adverse selection and governance problems associated with CCPs are to some extent mitigated by regulation which sets out prudential rules and risk management standards for CCPs, especially vis-à-vis margins, the guaranty fund and default waterfalls. These rules extend from establishing risk committees at the $\mathrm{CCP}$ level to international standards on liquidity lines and financial resources to address liquidity and solvency risk, ${ }^{26}$ and regular stress tests. ${ }^{27}$

Yet in spite of such prudential controls and especially the introduction of robust CCP stress testing, which have already identified the insufficiency of resources in extreme scenarios, ${ }^{28}$ the problems of containing and modelling CCP riskiness remain. Risk modelling is of critical importance when it comes to calibrating the guaranty fund contributions and the waterfall to avoid CCP failures. ${ }^{29}$ Roma Cont argues that:

Due to cross-membership of large financial across multiple CCPs and interoperating agreements between CCPs, isolated stress tests of single CCPs do not provide an accurate picture of losses in the event of the default of one or more clearing members. ${ }^{30}$

Therefore, a realistic assessment of the systemic risk associated with the failure of a clearing member calls for a stress test which accounts for the interconnectedness of different CCPs and their clearing members. ${ }^{31}$ Another obstacle with CCP stress testing is of course the fact that supervisors have extensive experience in bank stress testing and tend to treat CCPs as if they were banks, even though CCPs tackle entirely different (and often less diverse) types of risk and unlike banks they do not employ shareholders' capital as a key cushion against losses. ${ }^{32}$

\subsection{Industry Concentration and Risk Spillovers}

CCPs today have strong natural monopoly characteristics which decisively influence the structure of and competition within the clearing sector. This explains why the global marketplace is dominated by a very small number of large CCPs which tend to be highly systemically important. The view that there is a trade-off between

\footnotetext{
${ }^{26}$ Committee on Payments and Market Infrastructures, the Board of the International Organization of Securities Commissions (CPMI-IOSCO) (2012).

27 ESMA (2018); Committee on Payments and Market Infrastructures, the Board of the International Organization of Securities Commissions (CPMI-IOSCO) (2018).

28 E.g., ESMA (2018). Dan Hardie of risk.net notes: 'Small increases to stress-test scenarios would have left Ice Clear Europe “in material breach”'. Hardie (2018)

29 Two very important studies highlighting this problem are Cont (2015) and Armakolla and Laurent (2017).

30 Cont (2015), p 27.

31 Ibid., p 28.

32 See Cox and Steigerwald (2017).
} 
competition and systemic stability is nothing new and also pervades the banking sector literature. ${ }^{33}$ But even so, post-2008 regulation, if anything, strongly reinforced barriers to entry shoring up the competitive position of the very small number of $\mathrm{CCHs} / \mathrm{CCPs}$ that dominate the global industry for financial market infrastructure services.

CCPs are important inter-connectors in the financial system and are thus likely to be systemically important financial institutions. The failure of a large CCP can have potentially catastrophic consequences. And if the direct financial stability risks that such a concentration entails were not enough, the threat to the global disruption of the supply of clearing and settlement services ${ }^{34}$ or even a disruption in the operations of CCPs themselves, ${ }^{35}$ an unlikely but not impossible scenario, is too big to contemplate.

We discuss the problem of CCP and member interconnectedness in Sect. 4 below. It is sufficient to say here that possibly the only drastic (albeit long-term) remedy to the massive risks that CCP concentration poses is investment to accelerate the change of the technological paradigm so that CCPs become less systemically important/too-big-to-fail. Namely, the need to shift to a different technology paradigm may not be separated by clear concerns that show that big global CCPs are massive depositaries of systemic risk and a source of TBTF type of moral hazard.

\subsection{Standardization, Complexity and Liquidity}

The standardization of contract terms facilitates clearing in several ways. Most CCPs specialise in clearing specific asset classes which, on the one hand, facilitates post-trading/clearing liquidity, while, on the other, creates homogeneity of CCP exposures and a higher degree of industry concentration.

But the mandatory clearing of complex products creates risks for CCPs, since specialised firms have superior expertise in complex contracts putting CCPs at an information disadvantage vis-à-vis their members exacerbating the adverse selection problem. To resolve the issue of pricing the CCP will resort to either overcollateralization due to product underpricing or undercollateralisation, including lower than required initial margins, due to product overpricing. In the first case the CCP deprives the market of useful liquidity. In the second it remains under-protected against product risk.

Price information problems can be mitigated by prudent CCP policies. Still, product liquidity and pricing information, especially when it comes to complex products, will be very hard to obtain during periods of market stress due to a wider crisis and CCPs can find themselves badly exposed in the event of a member's default.

\footnotetext{
33 Ratnovksi (2013); Avgouleas (2016b).

${ }^{34}$ Financial Stability Board (2018), p 4. See also Financial Stability Board (2017a), p 3.

35 Ibid.
} 


\section{CCPS and Systemic Risk}

The key and often overlapping risks associated with CCPs tend to fall within four broad categories: (a) funding-liquidity shocks relating to both the supply of cash and collateral that spiral out of control; (b) the failure of critical CCP operations; (c) the failure of a CCP clearing member or connected party spilling over, coupled with the inadequacy of pre-funded CCP resources to cover an open position, and (d) the risk of interconnectedness, which is heightened due to the levels of concentration of CCP services and operators at the global level. ${ }^{36}$ In addition, the fact that the CCP itself and or its members may be too-big-to-fail can heighten moral hazard. As regards the solvency of the CCP itself much currency is given to having a proper system for the attribution of losses to the non-defaulting members (loss waterfall), a functional resolution framework that will make the failing CCP resolvable, facilitating orderly failure, and establishing proper liquidity assistance arrangements with the central bank. But none of these methods is failproof. ${ }^{37}$

\subsection{Funding Risks and Liquidity Shocks}

Margin collections are, in general, a sound mechanism to contain microprudential (counterparty default) risk. Yet sometimes changes in margin requirements can induce destabilizing trading. Firms that have to meet large margin calls may respond by selling assets and by reducing positions in ways that exacerbate the price changes which triggered the margin calls in the first place. As explained earlier, while margin calls reduce overall trader leverage at the same time they place pressure on members to obtain cash or other liquid assets to meet the calls within a short timeframe. This can give rise to considerable funding strains, which can drain market liquidity as they lead to interest rate rises and borrowing limits. Worse, they can directly lead to destabilizing price movements if CCP members liquidate assets in haste in their scramble for liquidity to meet the calls.

Given CCPs' ability to increase margin requirements with little notice such liquidations can turn into downward price spirals, which can for behavioural reasons, including panic and risk aversion, ${ }^{38}$ lead to systematic discounting and uncontrollable selling pressure. If solvent firms subject to margin calls have no other feasible course of action, because, for instance, a solvent CCP cannot meet immediate demands for the return of clearing member collateral, they will try to meet margin calls by resorting to firesales. These, in turn, impact the value of the balance sheets of all other firms holding similar assets in their portfolios. In this scenario margin calls become a classic example of a sound microprudential measure that can give rise to significant macroprudential risks. ${ }^{39}$ It is therefore arguable that central banks

\footnotetext{
${ }^{36}$ Financial Stability Board (2018).

37 For a critical overview see Cont (2015).

38 Avgouleas (2010).

39 Brunnermeier et al. (2009), pp 6, 7, 13, 14.
} 
could/should intervene in such a case to ease funding strains ${ }^{40}$ and especially to prevent firesales, ${ }^{41}$ which would turn margin calls into a system-wide price shock and that, in turn, into a wave of defaults. But resorting to Central Bank funding does increase moral hazard and adverse selection incentives making the decision to supply public liquidity support to CCPs less than straightforward.

\subsection{Member Failure and Inadequate Pre-Funded Resources}

In general, this type of risk refers to three types of failure. First, when a clearing member, identified as such at the clearing service level, defaults on its obligations. Such default exposes a CCP to credit and liquidity risks, because the CCP guarantees the fulfilment of obligations to surviving clearing members. If the CCP's pre-funded resources prove insufficient, the CCP might resort to a firesale of collateral it holds against the defaulting member to meet its liquidity and payment needs, eventually causing a firesales type of activity. Such actions exacerbate rather than contain a developing crisis due to the ensuing downward price spirals. Shortfalls in CCP pre-funded resources to meet exposures arising from a member's default due to member free riding and under-provisioning are not an everyday scenario given the prudential controls on the levels of CCP pre-funded resources. But still they are not an utterly remote risk.

\subsubsection{Margin Variations, Skin-in-the-Game, Default Funds and the Loss Waterfall Mechanism}

The presence of CCH's 'skin-in-the-game' in the 'default waterfall' aligns to some extent shareholder incentives with those of $\mathrm{CCH}$ members. In the case of a clearing member (CM) default, the CCP will, first, use the defaulter's Initial Margin and default fund contribution to cover the losses incurred (the defaulter pays approach), ${ }^{42}$ followed by a designated tranche of CCP capital, the so-called skin-inthe-game amount. If this proves insufficient, then the default waterfall is activated. The default waterfall describes how losses are reallocated across non-defaulting CMs. ${ }^{43}$ Firstly, the pre-funded default fund contributions of non-defaulting CMs will be used to cover the losses. Secondly, the CCP has to deploy recovery tools, such as the replenishment of the default fund, by demanding liquidity from non-defaulting CMs. Third, if the pre-funded contributions to the Default Fund are insufficient to cover all remaining losses, clearing members are required to provide the $\mathrm{CCP}$ with additional financial resources, so-called assessments.

At this point the waterfall can pose problems, because there may be payment delays from CMs and secondly because CCP's resilience is now exclusively dependent on the CMs' capacity to jointly bear losses given the replenishment of the default

\footnotetext{
40 Dobler et al. (2016), pp 13-18, 21, 22.

41 Avgouleas (2016a), pp 46, 47.

42 Pirrong (2011), p 43.

43 Elliott (2013), pp 5-8.
} 
fund's pre-funded resources and the skin in the game amount. In a distressed market, CMs' (lower) payment capability and (possibly) higher default probability may impact on their ability to raise (external) funding. ${ }^{44}$ Admittedly, in the case of some CCPs owned by very high-grade parent $\mathrm{CCHs}$, the $\mathrm{CCH}$ or its parent company, which would naturally be worried about reputation contagion, could intervene at this point with their own equity and liquidity resources. ${ }^{45}$

Of course, the higher the 'skin in the game ${ }^{46}$ and the clearer is the resolution framework on the fate of shareholders' equity in the event of CCP failure, the lower the moral hazard. $\mathrm{CCP} / \mathrm{CCH}$ owners may lose something in the event of a CCP failure in spite of eventual public support. On the other hand, this does not entirely preclude shareholders' opportunistic behaviour since there are many stages to an outright default and shareholders might have reaped the gains from profit earnings resulting from clearing riskier products for a long time.

\subsubsection{Variation Margin Haircuts (VMGH), Contract Tear-Ups, Initial Margin Haircuts}

Other forms of containing the fallout from a $\mathrm{CM}$ failure are: variation margin haircuts (VMGH), contract tear-ups, initial margin haircuts and the Central Bank liquidity assistance discussed above. VMGHs allocate losses similarly to what would occur in a resolution, namely, the CCP distributes remaining losses by recourse to pro rata unpaid gains at the beneficial owner level. VGMHs come after the 'loss waterfall' has been exhausted. ${ }^{47}$ They allow for the continuity of clearing services and enable the CCP to avoid the irreversibility and costs associated with a full resolution. VMGH can be efficient when losses arise from a large mark-to-market loss in instruments cleared by a CCP. ${ }^{48}$ However, they would not be sufficient when a member defaults due to losses in assets not cleared by the CCP. VGMHs and contract tear ups may provide temporary relief to the $\mathrm{CCP}$ in a stress scenario to avoid a costly and irreversible resolution procedure, but the impact of this news on the market may be impossible to control. ${ }^{49}$

\footnotetext{
${ }^{44}$ Tarullo (2015).

${ }^{45}$ E.g., Eurex Clearing AG, which is the $\mathrm{CCH}$ that operates the Eurex Clearing $\mathrm{CCP}$, is committed to provide additional financial resources as well, the so-called further dedicated amount. If this proves inadequate, Eurex Clearing's equity capital is applied to cover any remaining losses. In addition, in an illustration of the possible shortcomings of the ring-fencing of $\mathrm{CCPs}$ from the $\mathrm{CCH}$, in the case of Eurex the Deutsche Börse AG which is the mother company of both the Eurex Clearing CCH and Deutsche Borse has issued a letter of comfort in favour of Eurex Clearing, according to which Deutsche Börse AG, the ultimate parent company, will provide Eurex Clearing with financial funding to enable Eurex Clearing to comply with its obligations once all other sources of funding have been exhausted thereby preventing the failure of the CCP. See EurexClearing, 'Default Waterfall', available at http://www.eurexclearing.com/ clearing-en/risk-management/default-waterfall.

${ }^{46}$ Carter and Garner (2015), pp 85-86.

47 'The CCP would impose a haircut on cumulative variation margin ("VM") gains on the portfolio of trades of each beneficial owner which have accumulated over the days since the commencement of the default management process, i.e., day of the CM default giving rise to the Default Losses.' ISDA (2013), p 4.

${ }^{48}$ Ibid.

${ }^{49}$ Cont (2015), pp 32-33.
} 


\subsubsection{Contract Tear-Ups}

The possibility for the CCP to close certain unbalanced open positions provides a further backstop against continued losses. However, contract tear-ups result in a loss allocation across members which is not transparent ex ante and thus they do not provide clear incentives to clearing members. Also, they may appear as unfair ex post compared to a proper resolution procedure.

\subsubsection{Initial Margin Haircuts}

This is an uncommon recovery process under which the CCP (and/or the resolution authorities) uses funds serving as the initial margin of non-defaulted members to fund the CCP during recovery. Initial margin haircuts serve in this case in a similar fashion as the pre-committed member contributions to the Guaranty Fund thereby blurring the boundaries between the two. They can clearly increase/reduce members' exposures and distort member incentives. Essentially, a higher portion of nondefaulting members' funds is used to absorb the failure of the defaulting member to avoid CCP resolution. From the adverse selection point of view, it is much better to increase ex ante the size of the Guaranty Fund, which, however, makes CCP membership more expensive and, thus, even more clustered around a small number of systemically important and globally systemically important financial institutions (SIFIs and G-SIFIs) heightening the risk of interconnectedness discussed below.

\subsubsection{Provision of Central Bank Liquidity}

While this should be a plausible part of the recovery phase to avoid the worst case scenario which is CCP resolution, it still sends a very strong message to the market (when it is eventually disclosed) that the CCP is in great difficulties, save the moral hazard concerns discussed above. In addition, where the CCP clears in multiple currencies or the $\mathrm{CCP}$ and its members are registered in different jurisdictions there may be important political and practical (currency) obstacles in offering such assistance. ${ }^{50}$ Moreover, given that public money will be at stake in such a scenario, even pre-agreed multijurisdictional recovery and resolution plans might be torn apart on the day of reckoning without credit lines during recovery from multiple Central Banks or other sources. This is of course an important vulnerability in the execution of contemporary recovery and resolution frameworks for CCPs which engage in the clearing of cross-border and multi-currency trades.

\footnotetext{
${ }^{50}$ E.g., the swap lines between the European Central Bank (ECB) and the Bank of England which offer a vital liquidity backstop in connection with the clearing of euro FX trades on the London Clearing House have recently become the subject of much contended discussion, since the ECB intends to withdraw these liquidity support lines after the UK's exit from the EU. See Weber and Brush (2018). Among other powers the ECB demands in dealing with a crisis in 'foreign' clearinghouses is the power to ask such CCHs to increase collateral, limit cross-currency exposures, and shorten the intervals for their margin calls. Ibid.
} 


\subsection{CCP Operation Risks}

CCPs' resilience is also threatened by a variety of operating risks. The first type of operation risks refers to the disruption of intraday liquidity and settlement lines which CCPs maintain with intraday liquidity providers to minimize the risk of liquidity shortages or bottlenecks in orderly clearing. Such disruption exposes a CCP to operational and liquidity risks as payments and settlements may be delayed. Disruption with a provider of its overnight and term credit and liquidity facilities, on the other hand, exposes, the CCP to liquidity risks that might push the CCP to temporarily default on its payment obligations even if it holds enough pre-funded commitments.

Moreover, even when the CCP holds sufficient pre-funded commitments these are normally utilised as cash or non-cash investments and the default of a counterparty to a repo agreement with the CCP or a borrowing party, including a deposit-taking bank, can give rise to liquidity and operation risks as regards non-cash investments and non-cash collateral portfolios holding such assets (e.g., government bonds) with third-party investment managers with the purpose of generating an investment return. The failure of investment service providers may also expose CCPs to credit, operating and liquidity risks.

The second key source of operating risks for CCPs is when the operation of custodians, namely, firms that hold cash and securities collateral on behalf of CCPs and their members, is disrupted. Disruptions at a custodian firm exposes the client CCP to operational and liquidity risks, as the CCP may experience a delay in accessing its collateral and as the FSB notes: 'in case of cash collateral, the CCP may also face credit risks'. ${ }^{51}$

The third major type of CCP operating risks is when the operation of settlement banks is disrupted. Banks process payments and trade settlements and collateral transfers between CCPs and their members. As the FSB notes: '[d]isruptions at a settlement bank expose a CCP to operational risk (and possibly also credit and intraday liquidity risk) as it experiences delays in fulfilling payment and settlement obligations or transfers of collateral'. ${ }^{2}$

\subsection{Risk Concentration and Interconnectedness}

Risk concentration and its management is of course the key business of CCPs and it only becomes a concern when such centralisation becomes excessive due to members' adverse selection behaviour, a member failure, or a market-wide solvency or liquidity shock. But it also gives rise to visible and invisible ties of interconnectedness, which are heightened due to the concentrated nature of CCP services and operators at the global level.

\footnotetext{
51 Financial Stability Board (2018), p 6.

52 Ibid.
} 
An obvious concern is, for example, the fact that CCPs may be systemically important in more than one jurisdiction and that they maintain interdependencies with each other. ${ }^{53}$ They also develop very strong links with the rest of the financial system and especially systemically important and globally systemically important financial institutions (SIFIs and G-SIFIs) to which CCP members may belong, as a business division, or may be connected as affiliates or subsidiaries. In addition, CCPs maintain various relationships with other, non-member, financial institutions which may act as custodians, settlement banks, credit and liquidity providers and investment counterparties. Often a single entity maintains different types of relationships with different CCPs. As an example, a financial institution might be a member of one $\mathrm{CCP}$, a custodian for a second CCP, while providing a credit line to a third $\mathrm{CCP}{ }^{54}$

According to the FSB the largest 11 of the 306 clearing members globally are connected to between 16 and 25 CCPs, which, essentially, means that the default of a CCP clearing member could result in defaults of the same entity or its affiliates in up to 24 other CCPs. In fact, through cross-memberships, the links of interconnectedness between CCPs and CCPs and members run even deeper. ${ }^{55}$ Risk concentration in the CCPs is manifested beyond the obvious measure of CCP exposures in the fact that prefunded financial resources are concentrated at a small number of CCPs. As the FSB notes, the two largest CCPs (as measured by prefunded financial resources) account 'for nearly $40 \%$ of total prefunded financial resources provided to all CCPs'. 56

As explained in Sect. 5 below, DLT-based clearing systems might, in fact, prove to be catalysts in alleviating global risk concentration levels within CCPs and, to some extent, interconnectedness by encouraging a more diverse financial ecosystem when it comes to risk concentration flashpoints. The final settlement of netted positions will take place in Central Bank money but such settlement could be delayed or funded by system resources thus covering the open positions of the defaulting party. Arguably, the rules of such distribution should be very strict to battle adverse selection and moral hazard.

\section{Blockchain Technology for Derivatives Trading, Clearing and Settlement}

\subsection{Overview of the Issues}

Transferring the clearing of securities and of certain types (either very standardised or highly complex) derivatives contracts to DLT platforms could only act as a way

\footnotetext{
53 Financial Stability Board (2017e), pp 4-5.

54 Financial Stability Board (2018), p 4.

55 ' $[$ E]ven $[. .$.$] less highly connected CCPs often maintain connections to at least one highly connected$ entity that indirectly connects the CCP to the central (more interconnected) part of the network structure'. Ibid.

56 In fact this concentration factor has if anything worsened between 2016 and 2017 from 32 to $40 \%$. Ibid.
} 
to alleviate the burden on $\mathrm{CCHs}$ (and their revenue and member rent extraction ability). It will also reduce some of the visible and invisible links of interconnectedness that have developed between the large financial institutions that act as clearing members. This would both facilitate $\mathrm{CCH} / \mathrm{CCP}$ resolvability and augment the resilience of the financial ecosystem especially in the context of derivatives markets. Realistically DLT technology will be introduced in phases on an experimental and then pilot basis starting with more standardised OTC derivatives trading and clearing and eventually moving to the less standardised contracts. A recent FSB consultation paper identifies that while the centralisation of clearing and settlement was mostly conceived to draw bilateral OTC and non-standardised derivatives transactions in the latter case, CCPs have not made great inroads for contracts that are not subject to a mandatory clearing requirement. As the FSB notes ' $[$ s]ome categories of clients have less strong incentives to use central clearing and may have a lower degree of access to central clearing, ${ }^{57}$ Clearly the introduction of multiple DLT-based systems will resolve the issue of access without compromising transparency.

It is of course likely that the DLT platforms will also offer an integrated trading service attached to clearing and settlement services leading to the further economisation of transaction costs. This does not mean that CCPs will disappear or that they will cease to perform a valuable function. It means that clearing and settlement risk will become more diverse, less correlated and thus more manageable. It is not unreasonable to speculate that network effects might divert especially more standardised OTC derivatives trading and clearing to specialised DLT platforms. And while the platform itself will operate on the basis of margin requirements including margin calls and a system treasury acting as a guaranty fund, liquidity management may be more efficient. In any case the less concentration of correlated risk in a single CCP there is, the less the risk that a member or customer failure will cause the catastrophic consequences that a failure of any of today's CCPs may bring about.

\subsection{Essential Properties of DLT-Based Systems for Derivatives Clearing and Settlement}

It is expected that new types of systems for derivatives clearing and settlement will use open source protocols (such as e.g., hyperledger ${ }^{58}$ ) to configure DLT functionality and the type of smart contracts that users will exchange, which will have embedded in their code all rules for margin calls and variations, pricing updates etc., and will possibly communicate with regulatory rules/limitations as regards position limits, and other controls on trader exposures etc. ${ }^{59}$ Given the importance of concealing trader identities, it is envisaged that nodes in the ledger will create and

\footnotetext{
57 Bank of International Settlements, Financial Stability Board and IOSCO (2018), p 2.

58 Hyperledger is an open source collaborative effort created to advance cross-industry blockchain technologies. It is a global collaboration, hosted by The Linux Foundation, including leaders in finance and banking.

59 See White Paper, Project D-Chain, 19 December 2018, manuscript on file with the authors.
} 


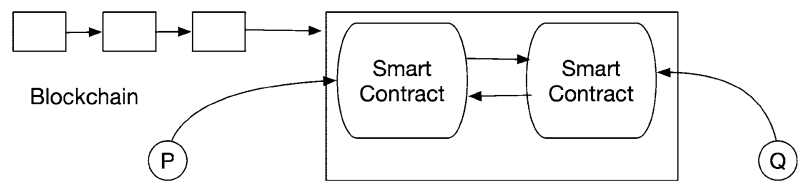

Fig. 1 Counterparties engage with a blockchain-based DLT issuing smart contracts that interoperate

use independent digital identities rooted in blockchains or other distributed ledgers which will be interoperable across administrative domains and applications. In addition, privacy-preserving techniques that are suitable for distributed ledgers are expected to be particularly useful in our context. ${ }^{60}$

The first generation of DLT systems based on the Bitcoin protocol and its variants provide basic transaction services around a single asset: accounts can be spontaneously created, and assets can be transferred from one account to another. Some more enhanced functionality is offered in the form of 'multi-sigs' where it is possible to create joint accounts following some arbitrary threshold access structure. While this functionality covers basic entity to entity asset transfers and simple account management, it is not sufficient for facilitating a robust market for OTC derivatives.

The second generation of DLT systems, such as Ethereum, provide a wider functionality that is consistent with futures contracts. Given the 'Turing-completeness' of second generation DLT systems it is possible to code arbitrary transaction systems so that they operate on top of the ledger. Nevertheless, there exist a number of critical considerations that need to be taken into account for implementing a fully functional derivatives exchange. We explain next in more detail the basic functionality that is required.

First, it is necessary to support a multi-asset environment that enables users to introduce new assets into the system and enable transfers between such assets. The transformation of an asset to a different one needs to be performed according to custom rules that should be specified by the issuer and may even be needed to be modified over time. An example of such a configuration between an investor and a broker is shown in Fig. 1. A critical feature here is that the multi-asset environment offered by the underlying DLT would be of most use if it allows the fluid interaction between all assets as opposed to a necessitated translation to a base native asset.

Assuming multiple assets and smart contracts, it is possible to facilitate margin accounts within a DLT environment. For simplicity, we will describe a scenario between a broker and an investor who wish to trade in derivatives for which a margin is maintained by the ledger from the outset with the investor aiming to acquire an amount of certain assets using some other assets as collateral. For the sake of simplifying our exposition let us assume that there is one asset to be acquired through an OTC forward contract, 'coffeecoins' (CC), and tokenised USD (T\$) is used for the payment of the premium or for settling the contract and US Treasury Bills (TTBs\$) are used as collateral.

${ }^{60}$ Examples of open DLT methods that provide enhanced privacy-preserving capabilities include ZChash, https://z.cash and Monero https://ww.getmonero.org. 


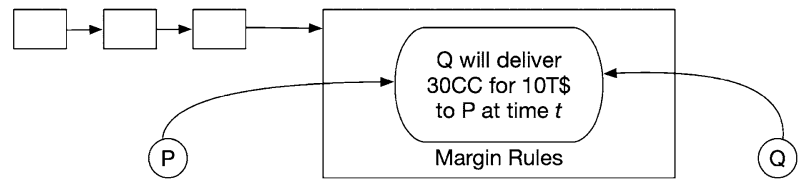

Fig. 2 A schematic representation of the blockchain and the smart contract setting up a margin position corresponding to a commodity forward contract. Margin rules are set system-wide and enforced by the software logic of the transaction ledger

We note that in both cases the tokenised assets could also be traded in the classical sense. In particular 1CC could be a pound of coffee of a specific type while translated into 1T\$ it would be a tokenised form of fiat USD currency. In either case the tokenised forms will be backed up by an issuer that also provides a functioning exchange that continuously ensures a stable 1:1 rate between the tokenised form of the asset and its real-world counterpart. Tokenised forms of fiat currency such as those used in the pilot case of the CAD-Coin experiment, which was successfully conducted by the Bank of Canada in the early stages of project Jasper, ${ }^{61}$ can be used for clearing.

Accordingly, when two counterparties enter into a smart contract with respect to acquiring an exposure for future delivery/or cash settlement over an index, a commodity like $\mathrm{CC}$, or another asset, the parties specify collateral in TTBs\$ as well as prescribed obligations in terms of delivery for CCs and tokenized T\$. The terms of such smart contract can be either determined fully off-chain and deployed on-chain with the understanding that it will be acceptable only in the case it conforms to the margin rules of the ledger, or they might be determined via a matching process that can also involve the ledger, with the parties posting relevant orders that are algorithmically matched by the ledger itself.

Once the contract is accepted by the ledger, which will require the margin rules to be satisfied, the smart contract becomes part of the margin accounts of the counterparties. Note that the value of the position is variable and depends on the exchange rate between $\mathrm{CC}$ and $\mathrm{T} \$$ which may also be extracted from blockchain data assuming that the ledger records sufficient market information.

The new smart contract may impose various timing restrictions in terms of its activation in the interface of the counterparties, but invariably if the margin call is not heeded it will ultimately enter dissolution mode where it may be substituted by another contract, or a selling state in its internal logic where CCs are made available in exchange for T\$. Various limitations can be imposed by the smart contract logic in terms of the ways the CCs can be traded. An important feature of the underlying DLT system is to inspect all outstanding contracts and attempt to net them en masse.

Referring to the example of Fig. 2, say party $\mathrm{P}$ is an investor acquiring CCs and $\mathrm{Q}$ is a broker that is responsible for the obligation to provide them. In such setting,

${ }^{61}$ Chapman et al. (2017) Project Jasper. 
it is not only the investor that can interact with the smart contract and ask for liquidating the CCs that are held by the contract. The broker may take action depending on the relative price between CCs and T\$. Such action can be initiated by the broker by issuing special maintenance transactions to the smart contract. The smart contract may have a margin maintenance requirement and in such a case a margin call will be issued by the broker. The investor has to deposit T\$ or TTBs $\$$ to meet the call.

In the above description there are two features that are atypical for standard DLT technology. First, smart contract logic requires to process extensive information about the state of other smart contracts that are running concurrently in the ledger as well as transactions that were issued by the participants and their results.

The second requirement is the ability to process orders in a settlement fashion at regular intervals between smart contracts. The ideal setting is obviously one where orders are perfectly matched. Nevertheless, the market may find itself in states where no such perfect matching is feasible or even worse in a liquidity crunch with respect to a specific asset. In this case, the DLT system's logic will have built-in mechanisms for liquidity savings to ensure an optimal liquidation strategy that attempts to minimise systemic risk within the DLT-based derivatives clearing system.

The 'nuclear'/ultimate resort option is to produce more assets of the required type as a way to meet the margin call or even, in a very limited number of cases, to settle the contract closing the position. In this case the system provides a temporary overdraft of proprietary currencies issued by its treasury functionality. This may only be a very last resort liquidity management facility and would operate under very strict and agreed upon ex ante parameters, which will have been preapproved by either authorised validators or regulators themselves. For this reason, the ledger will incorporate pre-approved parameters for the use of Treasury resources to temporarily cover an open position up to the point that a ledger participant either finds his/her own resources to cover his/her open position/margin call or the position is liquidated in an orderly manner. Certain game theory doctrines will be incorporated in the code/algorithm ${ }^{62}$ to avoid a situation whereby, similar to the famous Arrow impossibility theorem, ${ }^{63}$ validators will not be able to reach Pareto efficient decisions vis-à-vis alleviating liquidity bottlenecks on the platform.

Interoperability with legacy infrastructure is another important dimension in this respect and that includes Central Bank-controlled payment systems. But given the willingness of major Central Banks like the Bank of England to accept blockchain payments to be connected with or even to be processed through their own systems this ought not to be seen as an insurmountable problem. ${ }^{64}$

\footnotetext{
62 E.g., Polemarhakis and Geanakoplos (1982).

63 Arrow (1951).

64 E.g., The Bank of England announced on 23 July 2018 that it had completed a Proof of Concept (PoC) to understand how a renewed Real-Time Gross Settlement (RTGS) service could be capable of supporting settlement in systems operating on innovative payment technologies. Bank of England (2018). See also Carney (2018).
} 


\section{Securities Trading and Settlement Using Blockchain Technology- What Problems Would It Resolve?}

\subsection{Overview}

With the advent of digitisation and dematerialisation the paper certificates previously held directly under the name of investors in the registers of securities issuers securities are now held indirectly through intermediaries offering depositary services. These arrangements have generated serious rents for the intermediaries offering depositary/custodial services. As explained below the rents are twofold:

(a) Excessive intermediation and safekeeping fees and other costs. These are calculated, according to some studies, to be between 6 and $13 \%$ of the trade value chains that include execution, settlement, custody and collateral management services $^{65}$ and may reach up to $65-80$ billion USD per year ${ }^{66}$;

(b) Multiple agency relationships throughout the chain between the investor and the investment intermediaries where conflicts of interest may arise and intermediary rents may multiply. ${ }^{67}$

There are also costs vis-à-vis the dilution of investors' legal rights, ${ }^{68}$ a situation that is fully discussed below.

\subsection{Investor Rights and Intermediated Securities}

Under contemporary arrangements investors' securities are held indirectly through intermediaries, namely, they have become 'intermediated securities'. ${ }^{69}$ Investors merely receive statements about the value of their holdings ${ }^{70}$ and may still retain (or have duly delegated) the 'intrinsic rights' of the security (e.g., the right to vote, the right to receive a dividend) but their grip on the 'substantive' or otherwise proprietary rights with regard to title and other rights of enjoyment and the disposal of the security can become diluted in several ways.

Investors listed in the company registers used to be the legal owners of those securities, whereas investors holding through the custodial chain only have an equitable interest 'in another equitable interest of another equitable interest of a legal

\footnotetext{
65 The higher figure is based on a report by Wyman and SWIFT (2014), Exhibit 3, p 8 which found that revenue from settlement, custody and collateral management amounted to \$40-45 billion in 2013. Both the higher and lower figure are mentioned in a Bank of England staff paper by Benos et al. (2017), p 4.

66 Mainelli and Milne (2016), p 8.

67 See on the rise of intermediary power and agency capitalism: Gilson and Gordon (2013); Judge (2015).

68 See Micheler (2017). Eva Micheler was, in fact, among the first to identify this and explain the beneficial impact that DLT technology could have in this respect. See Micheler and von der Heyde (2016).

69 See Art. 1 of the Unidroit Convention on Substantive Rules for Intermediated Securities. On intermediated securities and the legal challenges they raise see Gullifer and Payne (2010).

70 Micheler (2015), pp 506-507.
} 
interest', a so-called 'interest in securities'. Under English law's concept of 'no look through' investors' rights are indirect. ${ }^{71}$ Namely, they can only claim against the immediate custodian who can then claim through the chain of sub-custodians who hold the requisite rights on the security on trust and so on.

Setting aside the dispute as to whether equitable rights are indeed proprietary rights, ${ }^{72}$ inevitably the custodial chain dilutes both investors' property rights and control over the use of their own assets that is now more or less delegated to the custodial intermediaries.

It is generally suggested that the 'no look through' approach facilitates liquidity especially as it makes it legally feasible to use the investor's/client's security as collateral in the context of securities lending and repo transactions. Both types of transaction buttress short-selling activity in the markets thereby averting default and may lubricate the flow of margin in derivatives markets or secure liquidity in certain types of secured financing. While these contracts are arranged by the custodian, they are also a source of income for the asset owner/end investor who normally permits such use of the asset under the terms and conditions of the initial custodial agreement. But as the custodian chain becomes longer and the asset moves ever more remotely, in spite of requisite legal and regulatory controls, ${ }^{73}$ the eventual legal accumulation of third-party interests does affect the value of investors' investments. ${ }^{74}$

\subsection{Collateral Re-use: Costs and Benefits}

According to the FSB non-cash collateral "is "re-used" when a market participant, such as a bank, receives securities as collateral in one transaction and subsequently sells, pledges or transfers this collateral in a second transaction' ${ }^{75}$ Collateral may be received by a market participant as a result of a variety of transactions, such as reverse repos, securities lending, margin lending and trades in over-the-counter (OTC) derivatives. If this collateral is eligible for re-use, the collateral taker can use it as collateral for other transactions. Collateral received may also be sold, creating a short position. ${ }^{76}$ Often these may involve collateral 'pledged for reuse' (rehypothecation $)^{77}$ whereby collateral takers have the right to re-use it in their own name. Its practical effect is economically equivalent to a title transfer (that is, a change in ownership) turning collateral into an instrument that is akin and equivalent to cash. In the pledged collateral market, any repo, securities lending, OTC derivatives (via a credit support annex) contracts and customer margin loans may involve a title transfer whereby the collateral provider transfers the ownership of collateral to the

\footnotetext{
71 See Law Commission Project on Intermediated Investment Securities, Second Seminar: issues affecting Account holders and Intermediaries, 23 June 2006, p 7.

72 The prevailing view, though, is that equitable rights under English law are proprietary. See on this Micheler (2015), pp 507, 523.

73 E.g., Client Assets sourcebook (CASS) 6.3.5 R FCA.

74 Micheler (2017).

75 Financial Stability Board (2017c), p 1.

76 Ibid.

77 Singh (2011), p 9.
} 
collateral taker. In return, the parties agree that once the collateral provider has discharged its financial obligation to the collateral taker, the collateral taker will return equivalent collateral to the collateral provider. Equivalent collateral means securities of the same type and value not the original security. ${ }^{78}$

The supply of collateral in this form plays a critical role in monetary policy transmission and may be used to expand credit/lending. ${ }^{79}$ On the other hand, there is a widespread view, mostly supported by the Financial Stability Board, that 'rehypothecation' can create a liquidity illusion which may be fleeting in times of stress, as proved to be the case in the 2007-2008 period $^{80}$ and may build obstacles to financial institutions resolution and insolvency because of the complex cross-ownership relationships that collateral re-use creates. ${ }^{81}$ Extensive rehypothecation can also be a source of systemic risk. In specific, it may:

(a) Lead to the accumulation of excessive leverage both at the individual entity and at the systemic levels;

(b) Increase interconnectedness in the financial sector, due to chains of transactions involving the re-use of collateral, reinforcing the risk of contagion, since one party's default (a failure to deliver re-used collateral) can lead to a further chain of failures;

(c) Increase the sensitivity of market participants to counterparty (credit) risk, especially in stressed conditions;

(d) Act as a procyclical risk transmission mechanism intensifying especially liquidity and solvency shocks;

(e) Amplify stress in the market, since a sudden drop in the value of widely held securities, which are re-used as collateral, will lead to substantial margin calls and higher haircuts, or even the exclusion of these securities from the pool of eligible collateral intensifying the liquidity and solvency strains facing market participants. $^{82}$

\subsection{DLT Benefits}

The introduction of DLT platforms for securities trading and settlement will have dramatic consequences in several areas. According to a Bank of England study whose critical findings we uphold, the shift in trade and post-trade technology can bring the following benefits:

- Reduction in reconciliation and data management costs since processes will be simplified and automated ${ }^{83}$;

- Flexible settlement times;

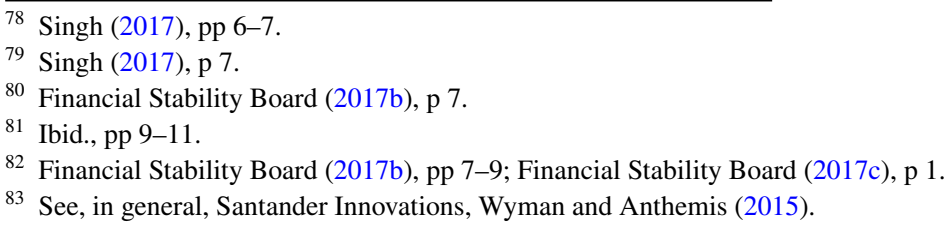


- The settlement risk will be drastically reduced if not eliminated;

- Automated clearing;

- Direct ownership instead of holdings of replacing intermediated securities;

- Traceability and transparency;

- Enhanced security and resilience. ${ }^{84}$

As explained above, DLT technology will facilitate the repatriation of control over traded securities where it belongs: the ultimate investor. This will result in an obvious reduction of legal and operational costs and would increase transparency, as investors could have direct access to their holdings and issuers could keep track of beneficial owners. ${ }^{85}$ It will also have a number of other consequences associated with such repatriation of control in addition to cost reductions.

Increased transparency in intermediary (asset managers' actions) and thus accountability could even resolve some of the problems identified by Professor Kay in his review of UK equity markets vis-à-vis the behaviour of market professionals. ${ }^{86}$ Such repatriation of control will give investors, particularly institutional investors, a direct say on how their securities are re-used, since it is beyond doubt that the practice will continue, to some extent, due to the fee income it generates. For example, in the case of pension funds and ethical and social market funds the fund trustees will have a much higher degree of control over the way managers permit their securities to be re-used, giving them the opportunity to reduce the availability of their collateral for highly leveraged/highly speculative transactions.

Naturally, all movements of the tokenised security will be traceable in a DLT environment. This also raises the possibility of protecting investor rights through the rehypothecation chain by using specifically designed and industry approved (for its fidelity) software. It is doubtful that such control will interfere with collateral transmission that is not placing investors' collateral in jeopardy or with collateral transfers used to facilitate the transmission of monetary policy. Finally, it will augment the effectiveness of the electronic methods and tools suggested by the FSB to measure 'collateral velocity' (including measures of collateral re-use), ${ }^{87}$ spotting in a timely manner 'financial stability risks arising from the re-use of collateral (e.g., interconnectedness, leverage and procyclicality)' to inform any policy responses to addressing these risks.

\subsection{Is the Introduction of DLT Technology in Securities Markets Feasible? Pace Jasper!}

In spite of the above, doubts remain about several aspects of the use of DLT for securities trading clearing and settlement. Even if the technology is there to achieve

\footnotetext{
${ }^{84}$ Mainelli and Milne (2016), p 8 and p 69.

85 See Micheler and von der Heyde (2016).

86 The Kay review of UK equity markets and long-term decision making, final report (July 2012), pp 9-10, available at http://www.law.harvard.edu/programs/corp_gov/long-term-value-creation-roundtable -2014-materials/kay-review_EX.pdf. Accessed 10 January 2019.

87 Financial Stability Board (2017c), pp 5 et seq., Appendix 1 and 2.
} 
the desirable rate of transactions per second, would system fidelity be so high as to preclude system failure and offer finality/certainty in securities trading, clearing and settlement? And if all these requirements are met is DLT more cost effective than legacy systems? While we will only know with certainty when the technology is put in widespread use the early signs are very encouraging. The challenges that are specific to the securities trading and post-trade environment have been summarised by the discussed Bank of England study as follows:

(a) The notary function which guarantees that the issued securities and any transfer of ownership are correctly recorded;

(b) The depository function: effective trading and clearing of securities via a shared ledger will require integrating the ledger with legacy assets;

(c) Delivery versus payment (DvP);

(d) Settlement finality;

(e) Legal ownership;

(f) Confidentiality;

(g) Identity management;

(h) Capacity to process a large number of trades at rapid speed (so-called Scalability). ${ }^{88}$

The strongest evidence yet that it is possible for DLT technology to achieve all of the above is offered by the findings of the Canadian project Jasper III. ${ }^{89}$ The experiment has shown that 'that it is feasible to instantaneously clear and settle securities on-ledger'. In particular, the proof of concept allowed clearing and 'delivery versus payment' settlement immediately, demonstrating that it is possible to complete post-trade settlement on a DLT platform. Jasper II achieved a proof of concept solution that shows that it is possible to deliver payments in a way that has never been done before-by directly swapping cash from buyers to sellers, resulting in instant settlements.

\section{Conclusion}

While CCPs' weaknesses in warehousing systemic risk may be a combination of structural flaws deeply ingrained in modern financial markets (e.g., interconnectedness) and market failures including business model flaws (e.g., adverse selection, inadequate pre-funded resources or skin-in-the-game), they still have served a useful purpose. Yet DLT systems can increase both risk and position visibility (while

\footnotetext{
88 Benos et al. (2017), pp 9-11.

89 Project Jasper is a collaborative project experiment conducted by Payments Canada, the Bank of Canada, TMX Group and Accenture to experiment with an integrated securities and payment settlement platform based on DLT. Jasper II is a continuation of earlier research work: Jasper I which examined the feasibility of the contested technology in the field of wholesale payments. It is a proof of concept experiment that was delivered by Accenture, leveraging R3's Corda DLT platform and explores the impact and potential benefits of DLT on broader Canadian financial market infrastructure.
} 
retaining market player anonymity) and cultivate a more diverse, and thus more capable to handle risk, ecosystem. In addition, increased investor control over their investments and enhanced post-trade transparency can curb leverage-fuelled excessive speculation. Therefore, the right time has arrived for regulators and other policy-makers to stop fighting the last crisis and to open the gates to regulatory experimentation, albeit, in the beginning, within a controlled environment. They should concentrate on how to foster the fidelity and reliability of DLT systems ${ }^{90}$ identifying (with industry's help) the best ways to build an effective loss distribution mechanism within the ledger.

Moreover, the use of blockchain technology in FMI, following experiments and pilot projects to augment the fidelity of relevant platforms/systems, has a strong transformational potential both structurally and in terms of a reduction of social costs for the benefit of global financial stability and investor welfare. It can also prove genuinely transformative beyond FMI. First, the discussed change in the technological paradigm can also lead to a radical reduction of industry rents for the benefit of end investors (supplies of finance) and end finance users increasing social gains at the expense of rent-seeking financial intermediaries. Second, the discussed change in the technological paradigm can create the right transparency, tradability, and liquidity conditions for long-term/committed finance to crowd out of the markets most of today's short-term/speculative activity that is largely wasteful. Namely, the low cost of markets and FMI based on DLT technology and increased transparency may give rise to network effects when it comes to the creation of liquid markets for previously illiquid investments like real assets, long-term infrastructure debt, social enterprise funding, and equity stakes in innovative start-ups. It is reasonable to expect that, given the strong social pressures institutional investors face today, especially with respect to sustainability, the creation of low cost and liquid markets in these instruments can lead to a change in market attitudes towards responsible/ ethical/long-term patterns of investment.

Open Access This article is distributed under the terms of the Creative Commons Attribution 4.0 International License (http://creativecommons.org/licenses/by/4.0/), which permits unrestricted use, distribution, and reproduction in any medium, provided you give appropriate credit to the original author(s) and the source, provide a link to the Creative Commons license, and indicate if changes were made.

\section{References}

Armakolla A, Laurent JP (2017) CCP resilience and clearing membership. 1 May 2017. http://dx.doi. org/10.2139/ssrn.2625579. Accessed 10 Jan 2019

Arrow KJ (1951) Social choice and individual values. Wiley, New York (republished in an extended form, 1963)

\footnotetext{
90 E.g., the South Korean capital markets regulator, the Financial Supervisory Service (FSS), issued an official report on 2 August 2018 which advises local regulatory agencies and companies to work towards developing an integrated blockchain system for stock transactions. See Wealth News Today, Finance, 'South Korea's Financial Watchdog Calls for Integrated Blockchain System for Stock Trading', 3 August 2018, http://www.wealthnewstoday.com/south-koreas-financial-watchdog-calls-for-integrated-blockchain -system-for-stock-trading/.
} 
ASX (2018) ASX outlines new features and timetable for DLT system to replace CHESS. Press Release, 27 April 2018. https://www.asx.com.au/documents/asx-news/asx-chess-replacement-scope-andimplementation-plan.pdf. Accessed 10 Jan 2019

Avgouleas E (2010) A new framework for the global regulation of short sales: why prohibition is inefficient and disclosure insufficient. Stanf J Law Bus Financ 15:376-425

Avgouleas E (2012) Governance of global financial markets. Cambridge University Press, Cambridge

Avgouleas E (2016a) Fundamentals of bank supervision and the lender of last resort in the post-2008 era: a critical appraisal and forward looking recommendations. Edinburgh School of Law Research Paper No 2016/24, November 2016. https://papers.ssrn.com/sol3/papers.cfm?abstract_id=2833891. Accessed 10 Jan 2019

Avgouleas E (2016b) Large systemic banks and fractional reserve banking. In: Buckley R, Avgouleas E, Arner D (eds) Reconceptualising global finance and its regulation, vol 14. Cambridge University Press, Cambridge

Bank of England (2018) RTGS renewal programme proof of concept: supporting DLT settlement models. 23 July 2018. https://www.bankofengland.co.uk/news/2018/july/rtgs-renewal-programme-proof-ofconcept-supporting-dlt-settlement-models. Accessed 10 Jan 2019

Bank of International Settlements, Financial Stability Board, IOSCO (2018). Incentives to centrally clear OTC derivatives - a post-implementation evaluation of the effects of the G20 financial regulatory reforms. 7 August 2018. https://www.bis.org/publ/othp28.pdf. Accessed 10 Jan 2019

Benos E, Garratt R, Gurrola-Perez P (2017) The economics of distributed ledger technology for securities settlement. Bank of England, Staff Working Paper Staff Working Paper No 670, August 2017

Bernanke B (1990) Clearing and settlement during the crash. Rev Financ Stud 3:133

Brunnermeier M, Crockett A, Goodhart C, Persaud AD, Shin H (2009) The fundamental principles of financial regulation. Geneva Reports on the World Economy 11. International Center for Monetary and Banking Studies (ICMB), Geneva

Carney M (2018) New economy, new finance, new Bank. Speech, 21 June 2018. https://www.banko fengland.co.uk/speech/2018/mark-carney-speech-at-the-lord-mayors-bankers-and-merchants-dinne r-mansion-house. Accessed 10 Jan 2019

Carter L, Garner M (2015) Skin in the game-central counterparty risk controls and incentives. Reserve Bank of Australia Bulletin, June Quarter. https://www.rba.gov.au/publications/bulletin/2015/jun/pdf/ bu-0615-9.pdf. Accessed 10 Jan 2019

Chapman J, Garatt R, Hendry S, McCormack A, McMahon W (2017) Project Jasper: are distributed wholesale payment systems feasible yet? Bank of Canada, Financial System Review, June 2017. https://www. bankofcanada.ca/wp-content/uploads/2017/05/fsr-june-2017-chapman.pdf. Accessed 10 Jan 2019

Committee on Payments and Market Infrastructures, the Board of the International Organization of Securities Commissions (CPMI-IOSCO) (2012) Principles for financial market infrastructures. April 2012. www. bis.org/cpmi/publ/d101a.pdf, www.iosco.org/library/pubdocs/pdf/IOSCOPD377-PFMI.pdf. Accessed 10 Jan 2019

Committee on Payments and Market Infrastructures, the Board of the International Organization of Securities Commissions (CPMI-IOSCO) (2018) Framework for supervisory stress-testing of central counterparties. April 2018. https://www.bis.org/cpmi/publ/d176.pdf. Accessed 10 Jan 2019

Cont R (2015) The end of the waterfall: default resources of central counterparties. Norges Bank, WP 16/2015. https://www.norges-bank.no/en/Published/Papers/Working-Papers/2015/162015/. Accessed 10 Jan 2019

Cox RT, Steigerwald RS (2017) A CCP is a CCP is a CCP. Federal Reserve Bank of Chicago, PDP 2017-01, April 2017

CSE (2018) CSE unveils Canada's first platform for clearing and settling securities through blockchain technology. Press Release, 13 February 2018 https://www.thecse.com/en/about/publications/cse-news/cseunveils-canadas-first-platform-for-clearing-and-settling-securities. Accessed 10 Jan 2019

Dobler M, Gray S, Murphy D, Radzewicz-Bak B (2016) The lender of last resort function after the global financial crisis. IMF Working Paper WP 16/10, January 2016

Duffie D, Zhu H (2011) Does a central counterparty reduce counterparty risk. Rev Asset Pricing Stud 1:7495. https://doi.org/10.1093/rapstu/rar001. Accessed 10 Jan 2019

Elliott D (2013) Central counterparty loss-allocation rules. Bank of England, Financial Stability Paper No 20, April 2013. http://www.eachccp.eu/wp-content/uploads/2015/12/Central-counterparty-loss-allocation -rules-Bank-of-England-Financial-Stability-Paper-No.-20.pdf. Accessed 10 Jan 2019 
ESMA (2018) Report EU-wide CCP stress test 2017. 2 February 2018. http://firds.esma.europa.eu/webst/ ESMA70-151-1154\%20EU-wide\%20CCP\%20Stress\%20Test\%202017\%20Report.pdf. Accessed 10 Jan 2019

Ferrarini G, Saguato P (2015) Governance and organization of trading venues: the role of financial market infrastructures groups. In: Busch D, Ferrarini G (eds) Regulation of the EU financial markets. Oxford University Press, Oxford, pp 285-314

Financial Stability Board (2017a) Analysis of central clearing interdependencies, first report. 5 July 2017. http://www.fsb.org/wp-content/uploads/P050717-2.pdf. Accessed 10 Jan 2019

Financial Stability Board (2017b) Transforming shadow banking into resilient market-based finance. Rehypothecation and collateral re-use: potential financial stability issues, market evolution and regulatory approaches. 25 January 2017. http://www.fsb.org/wp-content/uploads/Re-hypothecation-and-collateral -re-use.pdf. Accessed 18 Feb 2019

Financial Stability Board (2017c) Transforming shadow banking into resilient market-based finance noncash collateral re-use: measure and metrics. 25 January 2017. http://www.fsb.org/wp-content/uploads/ Non-cash-Collateral-Re-Use-Measures-and-Metrics.pdf. Accessed 10 Jan 2019

Financial Stability Board (2017d) Guidance on central counterparty resolution and resolution planning. 5 July 2017. http://www.fsb.org/2017/07/guidance-on-central-counterparty-resolution-and-resolution -planning-2/. Accessed 10 Jan 2019

Financial Stability Board (2017e) Chairs' report on the implementation of the joint workplan for strengthening the resilience, recovery and resolvability of central counterparties. 5 July 2017. http://www.fsb. org/2017/07/chairs-report-on-the-implementation-of-the-joint-workplan-for-strengthening-the-resil ience-recovery-and-resolvability-of-central-counterparties/. Accessed 10 Jan 2019

Financial Stability Board (2018) Analysis of central clearing interdependencies. 9 August 2018. http://www. fsb.org/2018/08/analysis-of-central-clearing-interdependencies-2/. Accessed 10 Jan 2019

Gilson RJ, Gordon JN (2013) The agency cost of agency capitalism: activist investors and the revaluation of governance rights. Columbia Law Rev 113:863-927

Gorton G, Metrick A (2009) Securitized banking and the run on repo. National Bureau of Economic Research. https://papers.ssrn.com/sol3/papers.cfm?abstract_id=1440752. Accessed 10 Jan 2019

Gullifer L, Payne J (eds) (2010) Intermediated securities_-legal problems and practical issues. Hart Publishing, Oxford

Hardie D (2018) CCP stress tests have found capital shortfalls-ESMA. risk.net, 5 February 2018. https:// www.risk.net/regulation/5403126/ccp-stress-tests-have-found-capital-shortfalls-esma. Accessed $10 \mathrm{Jan}$ 2019

Hartzmark ML (1986) The effects of changing margin levels on futures market activity, the composition of traders in the market, and price performance. J Bus 59:S147-S180

ISDA (2013) CCP loss allocation at the end of the waterfall. August 2013. https://www.isda.org/a/jTDDE/ ccp-loss-allocation-waterfall-0807.pdf. Accessed 10 Jan 2019

Judge K (2015) Intermediary influence. Univ Chic Law Rev 82:573-642

Kroszner RS (2011) Making the financial system more robust. In: Kroszner RS, Schiller RJ (eds) Reforming US financial markets. MIT Press Cambridge, Mass, pp 51-84

Mainelli M, Milne A (2016) The impact and potential of blockchain. Swift Institute Working Paper No 2015007, 9 May 2016. https://www.swiftinstitute.org/wp-content/uploads/2016/05/The-Impact-and-Poten tial-of-Blockchain-on-the-Securities-Transaction-Lifecycle_Mainelli-and-Milne-FINAL.pdf. Accessed 10 Jan 2019

Micheler E (2015) Custody chains and asset values: why crypto-securities are worth contemplating. Camb Law J 74:505-533

Micheler E (2017) Explaining the infrastructure underpinning securities markets-market failure and the role of technology. LSE, 16 May 2017. https://papers.ssrn.com/sol3/papers.cfm?abstract_id=2941643. Accessed 10 Jan 2019

Micheler E, von der Heyde L (2016) Holding, clearing and settling securities through blockchain/distributed ledger technology: creating an efficient system by empowering investors. J Int Bank Financ Law 11:652-656

Pirrong C (2006) Rocket science, default risk, and the organization of derivatives markets. https://www.bauer .uh.edu/spirrong/Derivorg1.pdf. Accessed 10 Jan 2019

Pirrong C (2009) The economics of clearing in derivatives markets: netting, asymmetric information, and the sharing of default risks through a central counterparty. http://dx.doi.org/10.2139/ssrn.1340660. Accessed 10 Jan 2019 
Pirrong C (2010) The inefficiency of clearing mandates. Cato Institute Policy Analysis No 665. http://www. cato.org/pubs/pas/PA665.pdf. Accessed 10 Jan 2019

Pirrong C (2011) The economics of central clearing - theory and practice. ISDA Discussion Paper 1, May 2011. https://www.isda.org/a/yiEDE/isdadiscussion-ccp-pirrong.pdf. Accessed 10 Jan 2019

Polemarhakis H, Geanakoplos J (1982) We can't disagree forever. J Econ Theory 28:192-200

Ratnovski L (2013) Competition policy for modern banks. IMF Working Paper WP/13/126, May 2013. http://citeseerx.ist.psu.edu/viewdoc/download?doi=10.1.1.364.7740\&rep=rep1\&type=pdf. Accessed 10 Jan 2019

Saguato P (2017) The ownership of clearinghouses: when 'skin in the game is not enough': the remutualization of clearinghouses. Yale J Reg 34:601-666

Santander Innovations, Wyman O, Anthemis (2015) The Fintech 2.0 paper: rebooting financial services. http://santanderinnoventures.com/wp-content/uploads/2015/06/The-Fintech-2-0-Paper.pdf. Accessed 10 Jan 2019

Singh M (2011) Velocity of pledged collateral: analysis and implications. IMF Working Paper, WP/11/256, November 2011. https://www.imf.org/external/pubs/ft/wp/2011/wp11256.pdf. Accessed 10 Jan 2019

Singh M (2017) Collateral reuse and balance sheet space. IMF Working Paper WP/17/113, May 2017

Singh M, Turing D (2018) Central counterparties resolution—an unresolved problem. IMF Working Paper No 18/65, March 2018

Tarullo DK (2015) Advancing macroprudential policy objectives. Speech at the Office of Financial Research and Financial Stability Oversight Council's 4th Annual Conference on 'Evaluating Macroprudential Tools: Complementarities and Conflicts. Arlington, 30 January

Telser L (1981) Why there are organized futures markets. J Law Econ 24:1-22

Weber A, Brush S (2018) ECB seeks new powers to deal with clearing crises outside the EU. Bloomberg, 18 April 2018. https://www.bloomberg.com/news/articles/2018-04-18/ecb-seeks-new-powers-to-dealwith-clearing-crises-outside-the-eu. Accessed 10 Jan 2019

Wyman O, SWIFT (2014) The capital markets industry-the times they are a changin'. https://www.olive rwyman.com/content/dam/oliver-wyman/global/en/files/insights/financial-services/2015/March/The _ Capital_Markets_Industry.pdf. Accessed 10 Jan 2019

Publisher's Note Springer Nature remains neutral with regard to jurisdictional claims in published maps and institutional affiliations.

\section{Affiliations}

\section{Emilios Avgouleas ${ }^{1,2,3} \cdot$ Aggelos Kiayias $^{4,5}$}

Aggelos Kiayias

aggelos.kiayias@ed.ac.uk

1 Chair in International Banking Law and Finance, University of Edinburgh, Edinburgh, UK

2 Visiting Research Professor, Faculty of Law, Hong Kong University, Hong Kong, People's Republic of China

3 Senior Fellow and Visiting Professor, School of European Political Economy, LUISS, Rome, Italy

4 Chair in Cyber Security and Privacy, School of Informatics, University of Edinburgh, Edinburgh, UK

5 Director of Blockchain Technology Laboratory, School of Informatics, University of Edinburgh, Edinburgh, UK 